\title{
ORIGINAL ARTICLE \\ Effect of MW-assisted roasting on nutritional and chemical properties of hazelnuts
}

\author{
Fatih Kalkan*, Sai Kranthi Vanga, Yvan Gariepy and Vijaya Raghavan \\ Department of Bioresource Engineering, Faculty of Agriculture and Environmental Studies, McGill University, \\ Sainte-Anne-de-Bellevue, QC, Canada
}

\begin{abstract}
In order to enhance the flavor, texture, color, and appearance of hazelnuts, they are roasted during postharvest processing. In this study, raw hazelnuts (Corylus avellana L.) were roasted using microwave (MW) and MWassisted hot air methods under various roasting conditions. The hazelnuts roasted were then examined to determine the percent DPPH radical scavenging activity, antioxidant capacity, total phenolic content, resistant starch, non-resistant starch, total starch, and protein concentration. The roasting experiments were done using a completely randomized factorial arrangement of two roasting types by three roasting times $(9,15$, and $21 \mathrm{~min})$ by three roasting temperatures $\left(70,90\right.$, and $\left.110^{\circ} \mathrm{C}\right)$ using three replications within each experiment. These roasting methods were found to yield significant differences in antioxidant capacity, total phenolic content, resistant starch, non-resistant starch, and protein concentration between MW and MW-assisted hot air roasting processes, while no difference was found in percent DPPH radical scavenging activity and total starch. The results obtained may be of great importance to the food research community and industrial hazelnut roasting technologies.
\end{abstract}

Keywords: microwave roasting; microwave-assisted hot air roasting; antioxidant activity; resistant starch; protein concentration

$\mathrm{M}$ ost of the world's hazelnuts (Corylus avellana L.) are grown in Turkey (72\%; 660,000 tonnes), and almost all are produced in the Black Sea region alone on more than 400,000 ha. Turkey is followed by Italy, the United States, and Spain in hazelnut production (1). The hazelnut is a tree nut; other tree nuts include the almond, Brazil nut, cashew, hazelnut, macadamia nut, pecan, pine nut, pistachio, and walnut. In the world market, tree nuts are segmented into two main groups, in-shell and shell tree nuts. In-shell nuts are the ones that are produced and marketed with the shell intact. However, tree nuts used in the food industry are mostly shelled, where the external shell is removed from the nut using any mechanical processing methods. Shelled nuts are then exposed to various processing methods including blanching, dicing, coating, roasting, or grinding (and combinations of the above methods) to get a properly prepared product and increase consumer appeal (2).

Hazelnuts are roasted for several reasons, primarily to enhance the flavor, texture, color, and appearance of the product significantly. In a few cases various treatments may also ensure the destruction of any toxins or allergens that may exist in the hazelnut. (2-4). Changes in flavor, texture, and color during the roasting process are primarily related to drying and non-enzymatic browning of the hazelnuts (5-7). Non-enzymatic browning is caused by heat treatments and generally includes several kinds of reactions including the Maillard reaction, caramelization, chemical oxidation of phenols, and maderization (8). Kim et al. reported that brown color, antioxidant activity, and flavor in agricultural products increases due to the Maillard reaction during the roasting process (9). Kim et al. also reported that roasting small black soybeans at higher temperatures and longer roasting times caused an increase in the degree of browning and antioxidant activity (9). The use of natural antioxidants has increased recently due to concerns regarding the safety of synthetic ones, even though several synthetically obtained antioxidants such as BHT (butylated hydroxytoluene), BHA (butylated hydroxyanisole), propyl gallate (PG), and ethyl protocatechuate (EP) are extensively used in the food industry and the human diet (10). Overall, the nutritional as well as other properties of agricultural products may be improved by application of a thermal treatment such as drying or roasting $(2-4,9,11-14)$.

Scientific reports on the physicochemical and nutritional properties of hazelnuts roasted by microwave (MW) 
and MW-assisted hot air are very scarce, and the current study will help to fill this gap in the literature. Hence, MW and MW-assisted hot air roasting techniques were applied to raw hazelnuts, which were then examined to determine the percent DPPH radical scavenging activity, antioxidant capacity, total phenolic content, resistant starch, nonresistant starch, total starch, and protein concentration.

\section{Materials and methods}

\section{Reagents}

Materials included methanol (Fisher Chemicals, A452-4, UK), ethanol (Fisher Chemicals, A962-4, UK), 2,2diphenyl-1-picrylhydrazyl (DPPH) (Sigma-Aldrich, D9132, USA), BHA (Sigma-Aldrich, B1253, USA), gallic acid (Sigma-Aldrich, G7384, USA), Folin-Ciocalteu's phenol reagent (Sigma-Aldrich, F9252, USA), anhydrous sodium carbonate (Fisher Chemicals, S263-1, UK), maleic acid (Sigma-Aldrich, M0375, USA), sodium hydroxide (American Chemicals, S290, USA), calcium chloride dihydrate (Fisher Chemicals, C79-500, UK), sodium azide (Sigma-Aldrich, S2002, USA), potassium hydroxide (Fisher Chemicals, S71978, UK), glacial acetic acid (Fisher Chemicals, A38-500, UK), Megazyme resistant starch assay kit (Megazyme International Ireland Ltd, Bray, Ireland), and Pierce ${ }^{\mathrm{TM}}$ BCA protein assay kit (Pierce, Rockford, IL, USA).

\section{Sample preparation}

Hazelnuts ( $C$. avellana L., Jumbo Barcelona variety) used in this study were purchased from a local market (Hazelnut Growers of Oregon, USA) as in-shell nuts. They were cracked by hand, and broken kernels were then removed from the bulk. Before the experiment, the initial moisture content of the hazelnuts was determined (15); it was found to be $5.7 \%$ d.b.

\section{Automated MW-assisted thermal system}

The roasting process was performed using an automated MW-assisted thermal system designed in the post-harvest technology laboratory (Macdonald Campus, McGill University). The automated MW-assisted thermal system was capable of both MW and MW-assisted hot air roasting processes. This system consisted of an air blower, air heaters, an MW chamber with balance, magnetron device, MW meter, waveguides, temperature-measuring devices such as thermocouples and fiber optic cables, and a data acquisition system. The MW generator operated at 2,450 $\mathrm{MHz}$ with variable power from 0 to $750 \mathrm{~W}$. The thermocouples, fiber optic cables (Nortech EMI-TS series, Quebec City, Canada), and balance were connected to an Agilent 34970A data acquisition system (Agilent Technologies, Santa Clara, CA, USA), and this system was also connected to a computer.

\section{Experimental procedure \\ MW experiments}

MW experiments were carried out using a completely randomized factorial arrangement of two roasting types by three roasting times by three roasting temperatures using three replications within each experiment. Hazelnut samples of $90 \pm 1 \mathrm{~g}$ were subjected to MW and MWassisted hot air roasting processes for 9, 15, and $21 \mathrm{~min}$ at temperatures of 70,90 , and $110^{\circ} \mathrm{C}$. MW power density was maintained at $1.1 \mathrm{~W} / \mathrm{g}$ during all experiments. Samples were placed in a single layer on the mesh sample holder, which was attached to a balance. In the MWassisted hot air roasting process, the air was heated by three 2-kW heaters and continuously circulated through the mesh by the blower, which had $0.2 \mathrm{~kW}$ of power and was placed below the roasting cavity. The temperature of the hazelnuts was measured during the roasting process with the help of an optical fiber probe.

\section{Hazelnut extraction}

Two grams of hazelnut powder was extracted in $25 \mathrm{ml}$ of $99.9 \%(\mathrm{v} / \mathrm{v})$ methanol at room temperature by stirring for $24 \mathrm{~h}$ at $175 \mathrm{rpm}$ and then filtering through Whatman Grade 4 filter paper Whatman (Clifton, NJ, USA). These extracts were analyzed for their antioxidant activity, total phenol content, and protein concentration.

Percent DPPH radical scavenging activity and antioxidant capacity Percent DPPH radical scavenging activity and antioxidant capacity were determined using DPPH free radical, which was a modification of the method from Ohinishi et al. (16). An aliquot of hazelnut powder extract solution $(270 \mu \mathrm{l})$ was added to $1,620 \mu \mathrm{l}$ of DPPH solution $(0.00394$ g DPPH per $100 \mathrm{ml}$ of $99.9 \%$ (v/v) methanol). After 20 min of incubation in the dark, the absorbance values were recorded at $517 \mathrm{~nm}$ (Ultrospec 2100 pro, Biochrom Ltd., Cambridge, UK). The reference was 99.9\% (v/v) methanol. Free radical scavenging activity on DPPH radicals was expressed as percent $(\%)$ inhibition:

Scavenging activity $(\%)=100 \times\left(\frac{\mathrm{Abs}_{\text {blank }}^{517 \mathrm{~nm}}-\mathrm{Abs}_{\text {sample }}^{517 \mathrm{~nm}}}{\mathrm{Abs}_{\text {blank }}^{517 \mathrm{~nm}}}\right)$

So as to express antioxidant capacity, a standard curve of BHA was obtained from DPPH radical scavenging activity (\%) plotted against various BHA concentrations. The concentrations of BHA solution were 2.5, 5, 10, 15, 20,25 , and $30 \mu \mathrm{g} / \mathrm{ml}$ of $99.9 \%(\mathrm{v} / \mathrm{v})$ methanol. All data were the average of triplicate analyses.

\section{Determination of total phenolic content}

Total phenolic content was determined according to the Folin-Ciocalteu procedure (17) with minor modifications. The hazelnut powder extract solution $(320 \mu \mathrm{l})$ and standard solution of gallic acid $(320 \mu \mathrm{l})(50,100,150$, 
$200,250,300$, and $350 \mu \mathrm{g} / \mathrm{ml}$ of $99.9 \%$ (v/v) methanol) were added to a $15 \mathrm{ml}$ volumetric capped tube. A reagent reference was prepared by using $99.9 \%(\mathrm{v} / \mathrm{v})$ methanol, $10 \%$ (v/v) Folin-Ciocalteu reagent, $7.5 \%$ (v/v) $\mathrm{Na}_{2} \mathrm{CO}_{3}$ solution, and deionized water. To the samples and standard solutions were added 1,280 $\mu 1$ of $10 \%(\mathrm{v} / \mathrm{v})$ Folin-Ciocalteu reagent and $800 \mu \mathrm{l}$ of $7.5 \%$ (v/v) $\mathrm{Na}_{2} \mathrm{CO}_{3}$ solution in succession; the mixtures were then shaken for $10 \mathrm{sec}$. After $3 \mathrm{~min}, 1,600 \mu \mathrm{l}$ of deionized water was added to the mixtures and they were shaken for $10 \mathrm{sec}$. The mixtures were incubated for $30 \mathrm{~min}$ in a $40^{\circ} \mathrm{C}$ water bath and then cooled for $15 \mathrm{~min}$ at ambient temperature in the dark. The absorbance against the reagent reference was determined at $765 \mathrm{~nm}$. The total phenolic content was expressed as gallic acid equivalents (GAE) in milligrams per gram of dry sample, using a standard curve generated with gallic acid. All data were the average of triplicate analyses.

Determination of resistant starch, non-resistant starch, and total starch

Resistant starch, non-resistant starch, and total starch contents were analyzed using the Megazyme resistant starch assay kit.

In brief, $100 \pm 5 \mathrm{mg}$ of sample was weighed individually into screw-cap tubes. Pancreatic $\alpha$-amylase solution (10 mg $\mathrm{mL}^{-1}$ ) containing $4 \mathrm{~mL}$ of amyloglucosidase (AMG) (3 U $\mathrm{mL}^{-1}$ ) was then added to the tubes, which were subsequently incubated at $37^{\circ} \mathrm{C}$ while being continuously shaken (200 strokes/min) for exactly $16 \mathrm{hr}$. After incubation, $4 \mathrm{~mL}$ of ethanol $(99.9 \% \mathrm{v} / \mathrm{v})$ was added to the tubes to aid dispersion, with vigorous stirring on a vortex mixer; the tubes were then centrifuged at $1,500 \mathrm{~g}$ for $10 \mathrm{~min}$. The supernatant was decanted and kept for nonresistant analysis. The pellets were resuspended in $2 \mathrm{~mL}$ of ethanol $(50 \% \mathrm{v} / \mathrm{v})$ with vigorous stirring on a vortex mixer; another $6 \mathrm{~mL}$ of ethanol $(50 \% \mathrm{v} / \mathrm{v})$ was added, and the mixture was centrifuged again at $1,500 \mathrm{~g}$ for $10 \mathrm{~min}$. This suspension and centrifugation process was repeated once more.

Determination of resistant starch. The pellets were resuspended with $2 \mathrm{~mL}$ of $2 \mathrm{M} \mathrm{KOH}$ and stirred for $20 \mathrm{~min}$ in an ice bath with a magnetic stirrer. Next, $8 \mathrm{~mL}$ of $1.2 \mathrm{M}$ sodium acetate buffer $(\mathrm{pH}$ 3.8) was added to the tubes as the mixture was stirred by the magnetic stirrer and then $0.1 \mathrm{~mL}$ of AMG ( $3 \mathrm{U} \mathrm{mL}^{-1}$ ) was immediately added. The mixture was stirred well and kept in a water bath at $50^{\circ} \mathrm{C}$ for $30 \mathrm{~min}$. After incubation, the tubes were directly centrifuged at $1,500 \mathrm{~g}$ for $10 \mathrm{~min}$. A $0.1 \mathrm{~mL}$ aliquot of the supernatant was treated with $3.0 \mathrm{~mL}$ glucose oxidase/ peroxidase (GOPOD) reagent and incubated at $50^{\circ} \mathrm{C}$ for 20 minutes. Sodium acetate buffer $(0.1 \mathrm{M}, \mathrm{pH} 4.5)$ and glucose $(1 \mathrm{mg} / \mathrm{mL}$ in $0.2 \%$ benzoic acid) were used as a blank and glucose standard, respectively. The absorbance was measured using a spectrophotometer at $510 \mathrm{~nm}$. Resistant starch (g/100 g sample) was calculated using an equation from the kit manual. The analyses were carried out twice.

Determination of non-resistant starch. The supernatant obtained from centrifugation was adjusted to $100 \mathrm{~mL}$ with $0.1 \mathrm{M}$ sodium acetate buffer $(\mathrm{pH} \mathrm{4.5)}$. A $0.1 \mathrm{~mL}$ aliquot of supernatant was incubated with $10 \mu \mathrm{L}$ of dilute AMG solution ( $3 \mathrm{U} \mathrm{mL}^{-1}$ ) in $0.1 \mathrm{M}$ sodium maleate buffer ( $\mathrm{pH}$ 6.0) for $20 \mathrm{~min}$ at $50^{\circ} \mathrm{C}$ and followed by a second incubation with $3.0 \mathrm{~mL}$ of GOPOD reagent for a further $20 \mathrm{~min}$ at $50^{\circ} \mathrm{C}$. The absorbance was recorded at $510 \mathrm{~nm}$ against a reagent blank. Non-resistant starch (g/100 g sample) was calculated using an equation from the kit manual. The analyses were carried out twice.

Total starch was obtained from the sum of resistant starch and non-resistant starch, as seen from Equation 8.

Total $\operatorname{starch}=$ resistant $\mathrm{starch}+$ non-resistant $\mathrm{starch}$

Determination of protein concentration

Protein concentration was analyzed using a Pierce BCA protein assay kit standardized with bovine serum albumin (BSA).

\section{Results and discussion}

The percent DPPH radical scavenging activity, antioxidant capacity, total phenolic content, resistant starch, non-resistant starch, total starch, and protein concentration were determined for both unroasted and roasted hazelnuts (see Table 1). After determining these properties, we examined their differences before and after the roasting process.

Effect of MW and MW-assisted hot air roasting process on percent DPPH radical scavenging activity and antioxidant capacity

In order to evaluate the ability of antioxidants to the scavenge free radicals, the percent DPPH radical scavenging assay is extensively used. Absorbance values recorded at $517 \mathrm{~nm}$ decrease with progression of the reaction

Table 1. Properties of unroasted hazelnuts

\begin{tabular}{lc}
\hline Properties & \multicolumn{1}{c}{ Values } \\
\hline Percent DPPH radical scavenging activity & $50.88 \pm 4.23^{*}$ \\
Antioxidant capacity, mg of BHA/g of dry sample & $0.48 \pm 0.04$ \\
Total phenolic content, mg of GAE/g of dry sample & $0.74 \pm 0.08$ \\
Resistant starch, \% d.b. & $1.52 \pm 0.0 \mathrm{I}$ \\
Non-resistant starch, \% d.b. & $1.19 \pm 0.07$ \\
Total starch, \% d.b. & $2.7 \mathrm{I} \pm 0.08$ \\
Protein concentration, $\mu \mathrm{g}$ of BSA $/ \mathrm{ml}$ of extract & $154.99 \pm 3.32$ \\
\hline
\end{tabular}

*Mean \pm standard deviation. BHA, butylated hydroxyanisole; BSA, bovine serum albumin; GAE, gallic acid equivalents; DPPH, 2,2-diphenyl-Ipicrylhydrazyl. 
between antioxidant molecules and DPPH radicals. A lower absorbance value means higher antioxidant activity of an extract in terms of its hydrogen atomdonating capacity, indicating that it is, therefore, more potent $(18,19)$. Table 2 presents the percent DPPH radical scavenging activity of hazelnuts roasted by MW and MWassisted hot air roasters. Changes in the concentrations of DPPH radicals due to the scavenging ability of the roasting temperatures of 70,90 , and $110^{\circ} \mathrm{C}$ were not statistically substantial for $9 \mathrm{~min}$ of the roasting time in MW roasting process, whereas it was statistically significant in the MW-assisted hot air roasting process $(p<0.01)$. On the other hand, in both MW and MW-assisted hot air roasting processes, there was a statistically significant difference among percent DPPH scavenging activities at the roasting temperatures for both the 15- and 21-min roasting times $(p<0.01)$. Percent DDPH radical scavenging activity, which was 50.88 for unroasted hazelnuts, linearly increased with the roasting temperature up to $110^{\circ} \mathrm{C}$ for each roasting time in the MW-assisted hot air roasting process, whereas no similar trend was observed in the MW roasting process. In the MW roasting process, percent DDPH radical scavenging activity first increased between unroasted hazelnuts and hazelnuts roasted at $70^{\circ} \mathrm{C}$ for $9 \mathrm{~min}$ and then decreased with an increase in the roasting temperature. The highest percent DDPH radical scavenging activity was obtained at a roasting temperature of $90^{\circ} \mathrm{C}$ for the 15- and 21-min roasting times in the MW roasting process. As seen in Table 2, when hot air was applied in combination with MW to the hazelnuts, the percent DDPH radical scavenging activity increased up to the final roasting temperature $\left(110^{\circ} \mathrm{C}\right)$ at all the roasting times. It may be concluded that while higher temperatures such as $110^{\circ} \mathrm{C}$ may have has a negative effect on percent DPPH scavenging activity in the MW roasting process, they had a positive effect when the MW-assisted hot air roasting process was used. Overall, the highest percent DPPH scavenging activity was obtained at a roasting temperature of $90^{\circ} \mathrm{C}$ with a 21 -min roasting time, whereas the lowest one was obtained at $110^{\circ} \mathrm{C}$ with a 9-min roasting time in the MW roasting process. In the MW-assisted hot air roasting process, a $110^{\circ} \mathrm{C}$ roasting temperature presented the strongest percent DPPH scavenging activity when processed for $15 \mathrm{~min}$; the $70^{\circ} \mathrm{C}$ roasting temperature presented the weakest percent DPPH scavenging activity at a roasting time of $9 \mathrm{~min}$. Many previous studies have shown that thermal processing such as drying and roasting preserves health benefits by enhancing antioxidant activity, which supports the results of this study $(9,12-14)$. It may be said that it is possible to improve the nutritional quality of hazelnuts with percent DPPH scavenging activity by $\mathrm{MW}$ and $\mathrm{MW}$-assisted hot air roasting processes. In one of the studies mentioned above, Kim et al. compared the antioxidant effects of small black soybeans under different roasting process conditions using DPPH and ABTS assays (9). They reported that roasted small black soybeans exhibited significantly higher antioxidant activity than unroasted small black soybeans in the DPPH and ABST assays.

The changes in antioxidant capacity and the corresponding values of roasted hazelnuts are presented in Table 3. While unroasted hazelnuts have $0.48 \mathrm{mg}$ of BHA/g dry sample of antioxidant capacity, the roasting process resulted in increased antioxidant capacity in both MW and MW-assisted hot air processes under the roasting conditions studied. The highest antioxidant capacity was obtained at $90^{\circ} \mathrm{C}$ for all the roasting times in the $\mathrm{MW}$ roasting process $(p<0.01)$. By contrast, a linear increase in antioxidant capacity in the MW-assisted hot air process was observed with increased roasting temperature from 70 to $110^{\circ} \mathrm{C}$ at all the roasting times $(p<0.01)$. The antioxidant capacities of hazelnuts that were roasted in an MW

Table 2. Percent DPPH scavenging activities of hazelnuts in MW and MW-assisted hot air roasting processes

\begin{tabular}{|c|c|c|c|c|c|}
\hline \multirow[b]{2}{*}{ Roasting type } & \multirow[b]{2}{*}{ Time, $\min$} & \multicolumn{3}{|c|}{ Temperature, ${ }^{\circ} \mathrm{C}$} & \multirow[b]{2}{*}{ Mean } \\
\hline & & 70 & 90 & 110 & \\
\hline \multirow[t]{4}{*}{ MW } & 9 & $67.78 \pm 8.75 d^{\delta}$ & $64.74 \pm 6.12 d$ & $63.24 \pm 9.82 \mathrm{~d}$ & $65.25 \mathrm{a} *$ \\
\hline & 15 & $86.82 \pm 5.37 d$ & $87.79 \pm 6.93 \mathrm{e}$ & $75.59 \pm 7.19 f$ & $83.37 b$ \\
\hline & 21 & $82.55 \pm 5.27 d$ & $95.10 \pm 7.70 \mathrm{e}$ & $88.69 \pm 5.42 f$ & $88.78 c$ \\
\hline & Mean & 79.05 & $82.5 \mathrm{I}$ & 75.84 & $79.14 A^{f}$ \\
\hline \multirow[t]{4}{*}{ MW-assisted hot air } & 9 & $62.98 \pm 8.05 h^{\delta}$ & $70.76 \pm 10.34 i$ & $78.66 \pm 8.47 j$ & $70.80 d^{*}$ \\
\hline & 15 & $69.85 \pm 5.14 \mathrm{~h}$ & $89.82 \pm 1.92 \mathrm{i}$ & $94.78 \pm 0.77 j$ & $84.82 e$ \\
\hline & 21 & $72.82 \pm 2.84 h$ & $87.54 \pm 4.32 \mathrm{i}$ & $93.53 \pm 1.91 \mathrm{j}$ & $84.63 \mathrm{e}$ \\
\hline & Mean & 68.55 & 82.71 & 88.99 & $80.08 \mathrm{~A}$ \\
\hline
\end{tabular}

Mean \pm standard deviation. MW, microwave. *Means in the same column followed by the same lowercase letter are not significantly different $(p<0.0 \mathrm{I})$ by Duncan's multiple range test. ${ }^{\delta}$ Means in the same row followed by the same lowercase letter are not significantly different $(p<0.0 \mathrm{I})$ by Duncan's multiple range test. ${ }^{\mathrm{f}}$ Means in the same column followed by the same uppercase letter are not significantly different $(p<0.01)$ by Duncan's multiple range test. 
Table 3. Antioxidant capacities of hazelnuts in MW and MW-assisted hot air roasting processes (mg of BHA/g of dry sample)

\begin{tabular}{|c|c|c|c|c|c|}
\hline \multirow[b]{2}{*}{ Roasting type } & \multirow[b]{2}{*}{ Time, min } & \multicolumn{3}{|c|}{ Temperature, ${ }^{\circ} \mathrm{C}$} & \multirow[b]{2}{*}{ Mean } \\
\hline & & 70 & 90 & 110 & \\
\hline \multirow[t]{4}{*}{ MW } & 9 & $0.60 \pm 0.08 d^{\delta}$ & $0.93 \pm 0.10 \mathrm{e}$ & $0.91 \pm 0.15 \mathrm{e}$ & $0.82 a^{*}$ \\
\hline & 15 & $1.02 \pm 0.17 d$ & $1.20 \pm 0.05 \mathrm{e}$ & $0.92 \pm 0.22 \mathrm{~d}$ & $1.04 b$ \\
\hline & 21 & $0.95 \pm 0.12 \mathrm{~d}$ & $1.25 \pm 0.11 \mathrm{e}$ & $1.01 \pm 0.06 \mathrm{~d}$ & $1.07 \mathrm{c}$ \\
\hline & Mean & 0.85 & 1.13 & 0.95 & $0.98 A^{f}$ \\
\hline \multirow[t]{4}{*}{$M W$-assisted hot air } & 9 & $0.40 \pm 0.07 d^{\delta}$ & $0.60 \pm 0.09 e$ & $0.66 \pm 0.07 e$ & $0.55 a^{*}$ \\
\hline & 15 & $0.55 \pm 0.08 d$ & $0.74 \pm 0.02 \mathrm{e}$ & $1.08 \pm 0.0 \mathrm{If}$ & $0.79 b$ \\
\hline & 21 & $0.76 \pm 0.03 d$ & $0.92 \pm 0.05 \mathrm{e}$ & $0.99 \pm 0.02 f$ & $0.89 c$ \\
\hline & Mean & 0.57 & 0.75 & 0.91 & $0.75 B$ \\
\hline
\end{tabular}

Mean \pm standard deviation. BHA, butylated hydroxyanisole; MW, microwave. *Means in the same column followed by the same lowercase letter are not significantly different $(p<0.01)$ by Duncan's multiple range test. ${ }^{\delta}$ Means in the same row followed by the same lowercase letter are not significantly different $(p<0.01)$ by Duncan's multiple range test. ${ }^{\mathfrak{E}}$ Means in the same column followed by the same uppercase letter are not significantly different $(p<0.01)$ by Duncan's multiple range test.

roaster were mostly higher than those of hazelnuts that were roasted in an $\mathrm{MW}$-assisted hot air roaster under all the roasting conditions studied $(p<0.01)$. It may be inferred that the rise in antioxidant capacity may be negatively affected by hot air applied with MW in the hazelnut roasting process. The roasting temperature of $90^{\circ} \mathrm{C}$ yielded the highest antioxidant capacity $(1.25 \mathrm{mg}$ of $\mathrm{BHA} / \mathrm{g}$ dry sample) at a $21-\mathrm{min}$ roasting time using the MW roasting process, while the lowest antioxidant capacity $(0.60 \mathrm{mg}$ of $\mathrm{BHA} / \mathrm{g}$ dry sample) was obtained by roasting at $70^{\circ} \mathrm{C}$ for $9 \mathrm{~min}$. Whereas the highest antioxidant capacity (1.08 $\mathrm{mg}$ of $\mathrm{BHA} / \mathrm{g}$ dry sample) was obtained at $110^{\circ} \mathrm{C}$ for $15 \mathrm{~min}$ using the $\mathrm{MW}$-assisted hot air roasting process, the roasting temperature of $70^{\circ} \mathrm{C}$ presented the lowest antioxidant capacity $(0.40 \mathrm{mg}$ of $\mathrm{BHA} / \mathrm{g}$ dry sample) at $9 \mathrm{~min}$ of the roasting time. It is noteworthy that the lower temperature with lower roasting time may cause a decrease in antioxidant capacity using the MW-assisted hot air roasting process. Likewise, the antioxidant capacity of $0.40 \mathrm{mg}$ of BHA/g dry sample, obtained using the $\mathrm{MW}$-assisted hot air roasting process at $70^{\circ} \mathrm{C}$ for $9 \mathrm{~min}$, was lower than antioxidant capacity of unroasted hazelnuts. We have not found any information concerning the effects of MW hazelnut roasting conditions on antioxidant capacity. Nevertheless, in prior research, the antioxidant capacity of cocoa kernels subjected to different roasting treatments was determined by Summa et al. (20). Their research showed that the roasting time caused an increase in the antioxidant capacity of kernels, which supported our results.

\section{Effect of MW and MW-assisted hot air roasting process on total phenolic content}

Table 4 presents the total phenolic content of roasted hazelnuts, which are in accordance with published data $(21,22)$. Although no statistical differences were presented

Table 4. Total phenolic contents of hazelnuts in MW and MW-assisted hot air roasting processes (mg of GAE/g of dry sample)

\begin{tabular}{|c|c|c|c|c|c|}
\hline \multirow[b]{2}{*}{ Roasting type } & \multirow[b]{2}{*}{ Time, $\min$} & \multicolumn{3}{|c|}{ Temperature, ${ }^{\circ} \mathrm{C}$} & \multirow[b]{2}{*}{ Mean } \\
\hline & & 70 & 90 & 110 & \\
\hline \multirow[t]{4}{*}{ MW } & 9 & $0.98 \pm 0.17 d^{\delta}$ & $0.74 \pm 0.08 \mathrm{e}$ & $0.82 \pm 0.07 e$ & $0.85 a^{*}$ \\
\hline & 15 & $0.99 \pm 0.10 \mathrm{~d}$ & $1.06 \pm 0.14 d$ & $0.97 \pm 0.16 d$ & $1.00 \mathrm{~b}$ \\
\hline & 21 & $1.00 \pm 0.10 \mathrm{~d}$ & $1.37 \pm 0.12 \mathrm{e}$ & $0.99 \pm 0.13 d$ & $1.12 c$ \\
\hline & Mean & 0.99 & 1.06 & 0.93 & $0.99 \mathrm{~A}^{ \pm}$ \\
\hline \multirow[t]{4}{*}{ MW-assisted hot air } & 9 & $0.91 \pm 0.09 d^{\delta}$ & $1.39 \pm 0.16 \mathrm{e}$ & $1.53 \pm 0.14 f$ & $1.28 \mathrm{a}^{*}$ \\
\hline & 15 & $0.79 \pm 0.14 d$ & $0.92 \pm 0.05 \mathrm{e}$ & $1.35 \pm 0.08 \mathrm{f}$ & $1.02 \mathrm{~b}$ \\
\hline & 21 & $0.81 \pm 0.04 d$ & $0.95 \pm 0.08 \mathrm{e}$ & $1.22 \pm 0.13 f$ & $1.00 c$ \\
\hline & Mean & 0.84 & 1.09 & 1.37 & $\mathrm{I} .10 \mathrm{~B}$ \\
\hline
\end{tabular}

Mean \pm standard deviation. GAE, gallic acid equivalents; MW, microwave. *Means in the same column followed by the same lowercase letter are not significantly different $(p<0.01)$ by Duncan's multiple range test. ${ }^{\delta}$ Means in the same row followed by the same lowercase letter are not significantly different $(p<0.01)$ by Duncan's multiple range test. ${ }^{£}$ Means in the same column followed by the same uppercase letter are not significantly different $(p<0.0$ I) by Duncan's multiple range test. 
by the roasting temperature on the total phenolic content at the 15-min roasting time using the MW roasting process, the roasting temperature statistically affected the total phenolic content at the 9 - and $21-$ min roasting times $(p<0.01)$. The total phenolic content was also statistically affected by the roasting temperature using the MWassisted hot air roasting process at all the roasting times $(p<0.01)$. While the maximum total phenolic content was presented as $1.37 \mathrm{mg}$ of GAE/g dry sample at $90^{\circ} \mathrm{C}$ with a 21-min roasting time using the $\mathrm{MW}$ roasting process under the various roasting conditions studied, it was obtained as $1.53 \mathrm{mg}$ of GAE/g dry sample at $110^{\circ} \mathrm{C}$ with a 9-min roasting time using the $\mathrm{MW}$-assisted hot air roasting process. Hot air applied with an MW had a more positive effect on the total phenolic content at the 9-min roasting time for all roasting temperatures, and this effect then decreased with an increase in the roasting time using the MW-assisted hot air roasting process. The total phenolic content of hazelnuts roasted in the MW roaster were mostly lower than for hazelnuts roasted in the MW-assisted hot air roaster under all roasting conditions $(p<0.01)$. Potent statistical correlations were also observed between the total phenolic content and percent DPPH scavenging activity $(p<0.01, p<0.01)$ and antioxidant capacity $(p<0.01, p<0.05)$ in the MW and MWassisted hot air roasting processes, respectively.

Effect of MW and MW-assisted hot air roasting process on resistant starch, non-resistant starch, and total starch

The resistant starch, non-resistant starch, and total starch of roasted hazelnuts are given in Tables 5-7. No substantial differences were statistically observed in the levels of resistant starch of roasted hazelnuts over all roasting temperatures and times using both MW and MW-assisted hot air roasting processes. The levels of resistant starch for hazelnuts roasted using the MW roasting process ranged from between 1.22 and $1.48 \%$ d.b., which were lower than for unroasted hazelnuts. Among the roasting conditions, the highest level of resistant starch was found at $110^{\circ} \mathrm{C}$ with a 15 -min roasting time, and the lowest level was obtained by roasting at $70^{\circ} \mathrm{C}$ for $21 \mathrm{~min}$ using the $\mathrm{MW}$ roasting process. By comparison, the levels of resistant starch for hazelnuts roasted in the MW-assisted hot air roaster varied between 1.34 and $1.54 \%$ d.b. The roasting temperature of $110^{\circ} \mathrm{C}$ yielded the maximum level of resistant starch with the 15-min roasting time, whereas roasting at $90^{\circ} \mathrm{C}$ for $21 \mathrm{~min}$ yielded the lowest level of resistant starch using the MW-assisted hot air roasting process among all roasting conditions. Overall, as seen from Table 5, the levels of resistant starch of hazelnuts roasted using the $\mathrm{MW}$-assisted hot air roaster were higher than those of hazelnuts roasted using the MW roaster under all roasting conditions $(p<0.01)$. This trend may be contributed to by applying hot air with an MW. We concluded that the MW roasting process decreased the level of resistant starch compared to unroasted hazelnuts at all the roasting conditions, whereas using the MW-assisted hot air roasting process increased the level of resistant starch compared to that of unroasted hazelnuts at some roasting conditions and caused a smaller reduction than the MW roasting process. In this context, as reported by Pereira and Leonel (23), food processing techniques including sterilizing, drying in ovens, or drying at high temperatures increases the level of resistant starch (24). A study supporting our results also reported that the level of resistant starch of chickpeas and beans decreased with application of a thermal treatment by MW (25). Conversely, unlike the levels of resistant starch, the levels of non-resistant starch were statistically affected by the roasting temperature under some roasting conditions (Table 6). A similar trend was also observed for the level of total starch, since the level of non-resistant starch

Table 5. Levels of resistant starch of hazelnuts in MW and MW-assisted hot air roasting processes (\% d.b.)

\begin{tabular}{|c|c|c|c|c|c|}
\hline \multirow[b]{2}{*}{ Roasting type } & \multirow[b]{2}{*}{ Time, min } & \multicolumn{3}{|c|}{ Temperature, ${ }^{\circ} \mathrm{C}$} & \multirow[b]{2}{*}{ Mean } \\
\hline & & 70 & 90 & 110 & \\
\hline \multirow[t]{4}{*}{ MW } & 9 & $1.26 \pm 0.10 d^{\delta}$ & $1.33 \pm 0.11 \mathrm{~d}$ & $1.39 \pm 0.22 d$ & $1.33 \mathrm{a}^{*}$ \\
\hline & 15 & $1.38 \pm 0.16 \mathrm{~d}$ & $1.30 \pm 0.15 d$ & $1.48 \pm 0.13 d$ & $1.39 \mathrm{a}$ \\
\hline & 21 & $1.22 \pm 0.36 \mathrm{~d}$ & $1.25 \pm 0.18 d$ & $1.32 \pm 0.10 \mathrm{~d}$ & $1.27 \mathrm{a}$ \\
\hline & Mean & 1.29 & 1.29 & 1.40 & $1.33 \mathrm{~A}^{£}$ \\
\hline \multirow[t]{4}{*}{ MW-assisted hot air } & 9 & $1.40 \pm 0.16 d^{\delta}$ & $1.44 \pm 0.14 \mathrm{~d}$ & $1.53 \pm 0.22 \mathrm{~d}$ & $1.46 a^{*}$ \\
\hline & 15 & $1.40 \pm 0.20 \mathrm{~d}$ & $1.45 \pm 0.13 d$ & $1.54 \pm 0.16 \mathrm{~d}$ & $1.46 \mathrm{a}$ \\
\hline & 21 & $1.38 \pm 0.07 d$ & $1.34 \pm 0.03 d$ & $1.49 \pm 0.23 d$ & $1.40 \mathrm{a}$ \\
\hline & Mean & 1.39 & $1.4 \mathrm{I}$ & 1.52 & $\mathrm{I} .44 \mathrm{~B}$ \\
\hline
\end{tabular}

Mean \pm standard deviation. MW, microwave. *Means in the same column followed by the same lowercase letter are not significantly different $(p<0.0 \mathrm{I})$ by Duncan's multiple range test. 'Means in the same row followed by the same lowercase letter are not significantly different ( $p<0.0 \mathrm{I})$ by Duncan's multiple range test. ${ }^{f}$ Means in the same column followed by the same uppercase letter are not significantly different $(p<0.0 \mathrm{I})$ by Duncan's multiple range test. 
Table 6. Levels of non-resistant starch of hazelnuts in MW and MW-assisted hot air roasting processes (\% d.b.)

\begin{tabular}{|c|c|c|c|c|c|}
\hline \multirow[b]{2}{*}{ Roasting type } & \multirow[b]{2}{*}{ Time, min } & \multicolumn{3}{|c|}{ Temperature, ${ }^{\circ} \mathrm{C}$} & \multirow[b]{2}{*}{ Mean } \\
\hline & & 70 & 90 & 110 & \\
\hline \multirow[t]{4}{*}{ MW } & 9 & $1.13 \pm 0.40 \mathrm{~d}^{\delta}$ & $0.78 \pm 0.05 d$ & $0.84 \pm 0.14 d$ & $0.91 \mathrm{ab} *$ \\
\hline & 15 & $1.18 \pm 0.06 d$ & $0.94 \pm 0.16 \mathrm{e}$ & $0.87 \pm 0.14 \mathrm{e}$ & $1.00 \mathrm{a}$ \\
\hline & 21 & $0.74 \pm 0.06 \mathrm{~d}$ & $0.86 \pm 0.25 d$ & $0.86 \pm 0.15 d$ & $0.82 b$ \\
\hline & Mean & 1.01 & 0.86 & 0.86 & $0.91 A^{£}$ \\
\hline \multirow[t]{4}{*}{ MW-assisted hot air } & 9 & $0.75 \pm 0.05 d^{\delta}$ & $1.06 \pm 0.24 \mathrm{e}$ & $0.93 \pm 0.14 \mathrm{de}$ & $0.91 a^{*}$ \\
\hline & 15 & $1.25 \pm 0.17 d$ & $0.64 \pm 0.00 \mathrm{e}$ & $0.59 \pm 0.07 e$ & $0.83 a$ \\
\hline & 21 & $0.76 \pm 0.05 d$ & $0.57 \pm 0.04 \mathrm{e}$ & $0.6 \mathrm{I} \pm 0.2 \mathrm{Ide}$ & $0.65 b$ \\
\hline & Mean & 0.92 & 0.76 & 0.7 I & $0.80 \mathrm{~B}$ \\
\hline
\end{tabular}

Mean \pm Standard deviation. MW, microwave. *Means in the same column followed by the same lowercase letter are not significantly different $(p<0.0 \mathrm{I})$ by Duncan's multiple range test. 'Means in the same row followed by the same lowercase letter are not significantly different $(p<0.0 \mathrm{I})$ by Duncan's multiple range test. ${ }^{\mathfrak{A}}$ Means in the same column followed by the same uppercase letter are not significantly different $(p<0.0 \mathrm{I})$ by Duncan's multiple range test.

affected the level of total starch (Table 7). At the higher roasting temperatures and longer times in both MW and MW-assisted hot air roasting process, non-resistant starch particles were easily degraded into sugar, as seen from Table 6.

\section{Effect of MW and MW-assisted hot air roasting processes on protein concentration}

The initial level of protein concentration of unroasted hazelnuts was $154.99 \mu \mathrm{g}$ of $\mathrm{BSA} / \mathrm{ml}$ of extract. Table 8 presents the levels of protein concentrations for roasted hazelnuts, which were higher than those of unroasted hazelnuts for all the roasting conditions studied. There were no statistically significant differences among the levels of protein concentrations at the roasting temperatures using the MW roasting process for all the roasting times, however the roasting temperature statistically affected the levels of protein concentrations using MW- assisted hot air roasting process at all the roasting times studied. Such a trend may be contributed to by application of hot air with an MW. As seen from Table 8, while a linear increase was observed in the levels of protein concentrations with increasing roasting temperature using the $\mathrm{MW}$-assisted hot air roasting process at all the roasting times, it was not observed for the MW roasting process except under one condition, which already had no statistically significant effect. The highest protein concentration $(243.34 \mu \mathrm{g}$ of $\mathrm{BSA} / \mathrm{ml}$ of extract) was obtained using the $\mathrm{MW}$ roasting process at $110^{\circ} \mathrm{C}$ for $21 \mathrm{~min}$; this concentration was $57 \%$ higher than the protein concentration of unroasted hazelnuts. The MW-assisted hot air roasting process also increased the protein concentration by $105 \%$ at a $110^{\circ} \mathrm{C}$ roasting temperature and a $21-\mathrm{min}$ roasting time. This increase was for the highest level of protein concentration using the MW-assisted hot air roasting process. In this context, Locatelli et al. reported

Table 7. Levels of total starch in hazelnuts roasted using MW and MW-assisted hot air roasting processes (\% d.b.)

\begin{tabular}{|c|c|c|c|c|c|}
\hline \multirow[b]{2}{*}{ Roasting type } & \multirow[b]{2}{*}{ Time, $\min$} & \multicolumn{3}{|c|}{ Temperature, ${ }^{\circ} \mathrm{C}$} & \multirow[b]{2}{*}{ Mean } \\
\hline & & 70 & 90 & 110 & \\
\hline \multirow[t]{4}{*}{ MW } & 9 & $2.39 \pm 0.40 d^{\delta}$ & $2.11 \pm 0.11 d$ & $2.23 \pm 0.3 \mathrm{Id}$ & $2.24 a b *$ \\
\hline & 15 & $2.56 \pm 0.07 d$ & $2.24 \pm 0.17 \mathrm{e}$ & $2.36 \pm 0.16 \mathrm{e}$ & $2.38 \mathrm{a}$ \\
\hline & 21 & $1.96 \pm 0.37 d$ & $2.11 \pm 0.32 d$ & $2.18 \pm 0.21 d$ & $2.08 b$ \\
\hline & Mean & 2.30 & 2.15 & 2.25 & $2.24 A^{£}$ \\
\hline \multirow[t]{4}{*}{ MW-assisted hot air } & 9 & $2.14 \pm 0.20 \mathrm{~d}^{\delta}$ & $2.50 \pm 0.28 \mathrm{e}$ & $2.47 \pm 0.28 \mathrm{e}$ & $2.37 a^{*}$ \\
\hline & 15 & $2.65 \pm 0.30 d$ & $2.09 \pm 0.13 \mathrm{e}$ & $2.13 \pm 0.14 \mathrm{e}$ & $2.29 \mathrm{a}$ \\
\hline & 21 & $2.14 \pm 0.10 \mathrm{~d}$ & $1.92 \pm 0.07 d$ & $2.09 \pm 0.27 d$ & $2.05 b$ \\
\hline & Mean & 2.31 & 2.17 & 2.23 & $2.24 \mathrm{~A}$ \\
\hline
\end{tabular}

Mean \pm standard deviation. MW, microwave. *Means in the same column followed by the same lowercase letter are not significantly different $(p<0.0 \mathrm{I})$ by Duncan's multiple range test. ${ }^{\delta}$ Means in the same row followed by the same lowercase letter are not significantly different $(p<0.0 \mathrm{I})$ by Duncan's multiple range test. ${ }^{f}$ Means in the same column followed by the same uppercase letter are not significantly different $(p<0.0 \mathrm{I})$ by Duncan's multiple range test. 
Table 8. Levels of protein concentration in hazelnuts roasted using MW and MW-assisted hot air roasting processes ( $\mu \mathrm{g}$ of BSA/ml of extract)

\begin{tabular}{|c|c|c|c|c|c|}
\hline \multirow[b]{2}{*}{ Roasting type } & \multirow[b]{2}{*}{ Time, $\min$} & \multicolumn{3}{|c|}{ Temperature, ${ }^{\circ} \mathrm{C}$} & \multirow[b]{2}{*}{ Mean } \\
\hline & & 70 & 90 & 110 & \\
\hline \multirow[t]{4}{*}{ MW } & 9 & $199.47 \pm 31.17 d^{\delta}$ & $|87.2| \pm 4.89 d$ & $185.96 \pm 28.61 \mathrm{~d}$ & $190.88 \mathrm{a} *$ \\
\hline & 15 & $214.37 \pm 11.10 \mathrm{~d}$ & $219.91 \pm 27.70 d$ & $205.07 \pm 4.12 d$ & $213.12 b$ \\
\hline & 21 & $215.07 \pm 22.42 \mathrm{~d}$ & $236.5 I \pm 21.38 d$ & $243.34 \pm 20.79 d$ & $231.64 c$ \\
\hline & Mean & 209.64 & 214.54 & 211.46 & $211.88 \mathrm{~A}^{\mathfrak{f}}$ \\
\hline \multirow[t]{4}{*}{ MW-assisted hot air } & 9 & $179.44 \pm 17.30 d^{\delta}$ & $195.26 \pm 16.14 d$ & $260.4 \mathrm{I} \pm 42.79 \mathrm{e}$ & $211.70 a^{*}$ \\
\hline & 15 & $184.61 \pm 21.68 d$ & $233.59 \pm 12.59 e$ & $313.17 \pm 26.15 f$ & $243.79 b$ \\
\hline & 21 & $196.34 \pm 17.37 d$ & $240.19 \pm 23.67 e$ & $318.34 \pm 39.20 f$ & $251.62 c$ \\
\hline & Mean & 186.80 & 223.01 & 297.31 & $235.70 \mathrm{~B}$ \\
\hline
\end{tabular}

Mean \pm standard deviation. BSA, bovine serum albumin; MW, microwave. *Means in the same column followed by the same lowercase letter are not significantly different $(p<0.01)$ by Duncan's multiple range test. ${ }^{\delta}$ Means in the same row followed by the same lowercase letter are not significantly different $(p<0.01)$ by Duncan's multiple range test. ${ }^{\mathfrak{E}}$ Means in the same column followed by the same uppercase letter are not significantly different $(p<0.01)$ by Duncan's multiple range test.

that the protein content of medium roasted hazelnuts was lower than that of dark roasted hazelnuts, which supported our results (10). Higher levels of protein in roasted hazelnuts compared to unroasted hazelnuts may be explained by the protein digestibility. In their study, Kong and Singh (26) emphasized that the roasting process caused an increase in protein digestibility. In recent studies conducted by Vanga et al. similar results were observed where processing of peanuts increased the protein digestibility (27). Holter and Reid also reported that there was a relationship between level of protein concentration and level of protein digestibility of some forages (28). Overall, levels of protein concentration in hazelnuts roasted by the MW-assisted hot air roaster were higher than the levels of hazelnuts roasted by MW roaster, as seen from Table $8 \quad(p<0.01)$. This trend may be explained by application of hot air with an MW.

\section{Conclusions}

While percent DPPH scavenging activities ranged from between 63.24 and 95.10 in the MW roasting process, they varied between 62.98 and 94.78 in the MW-assisted hot air roasting process. The highest antioxidant capacity increased $160.4 \%$ at a $90^{\circ} \mathrm{C}$ roasting temperature and a 21-min roasting time using the MW roasting process compared to unroasted hazelnuts, while it increased $125 \%$ at $110^{\circ} \mathrm{C}$ and $15 \mathrm{~min}$ using the $\mathrm{MW}$-assisted hot air roasting process. The maximum total phenolic content was obtained using the $\mathrm{MW}$ roasting process at $90^{\circ} \mathrm{C}$ for $21 \mathrm{~min}$, whereas it was observed using the MW-assisted hot air roasting process at $110^{\circ} \mathrm{C}$ for $9 \mathrm{~min}$. Hot air applied with an MW on hazelnuts in the MW-assisted hot air roasting process caused a lesser reduction in levels of resistant starch compared to the MW roasting process. Non-resistant starch particles were easily degraded into sugar during higher roasting times in both the
MW and MW-assisted hot air roasting processes. Levels of protein concentration of hazelnuts roasted using the MW-assisted hot air roaster were higher than levels of hazelnuts roasted by the MW roaster under all the roasting conditions studied.

\section{Acknowledgements}

The authors thank the Scientific and Technological Research Council of Turkey, who provided funding to Fatih Kalkan.

\section{Conflict of interest and funding}

The authors have not received any funding or benefits from industry or elsewhere to conduct this study.

\section{References}

1. FAO. Available from: http://www.fao.org/2012 [cited 1 May 2015].

2. Demir AD, Baucour P, Cronin K, Abodayeh K. Analysis of temperature variability during the thermal processing of hazelnuts. Innov Food Sci Emerg Technologies 2003; 4: 69-84.

3. Demir AD, Cronin K. Modelling the kinetics of textural changes in hazelnuts during roasting. Simul Modelling Practi Theor 2005; 13: 97-107.

4. Wigotzki M, Steinheart H, Pashcke A. Influence of varieties, storage and heat treatment on IgE-binding proteins in hazelnuts (Corylus avellana). Food Agric Immunol 2000; 12: 217-29.

5. Ozdemir M, Seyhan FG, Bakan AK, Ilter S, Ozay G, Devres O. Analysis of internal browning of roasted hazelnuts. Food Chem 2001; 73: 191-6.

6. Mayer KP. Infra-red roasting of nuts, particularly hazelnuts. Confect Prod 1985; 51: 313-16.

7. Buckholz LL, Daun H, Stier E. Influence of roasting time on sensory attributes of fresh roasted peanuts. J Food Sci 1980; 45: 547-54.

8. Manzocco L, Calligaris S, Mastrocola D, Nicoli M, Lerici C. Review of nonenzymatic browning and antioxidant capacity in processed food. Trends Food Sci Tech 2011; 11: 340-6. 
9. Kim HG, Kim GW, Oh H, Yoo SY, Kim YO, Oh MS. Influence of roasting on the antioxidant activity of small black soybean (Glycine max L. Merrill). LWT - Food Sci Tech 2011; 44: 992-8.

10. Locatelli M, Travaglia F, Coïsson JD, Martelli A, Stévigny C, Arlorio M. Total antioxidant activity of hazelnut skin (Nocciola Piemonte PGI): impact of different roasting conditions. Food Chem 2010; 119: 1647-55.

11. Lee S, Lee J. Effects of oven-drying, roasting, and explosive puffing process on isoflavone distributions in soybeans. Food Chem 2009; 112: 316-20.

12. Jaramillo-Flores ME, González-Cruz L, Cornejo-Mazón M, Dorantes-Alvarez L, Gutiérrez-López GF, Hernández-Sánchez H. Effect of thermal treatment on the antioxidant activity and content of carotenoids and phenolic compounds of cactus pear cladodes (Opuntia ficus-indica). Food Sci Tech Int 2003; 9: 271-8.

13. Dewanto V, Wu X, Liu RH. Processed sweet corn has higher antioxidant activity. J Agric Food Chem 2002; 50: 4959-64.

14. Nicoli MC, Anese M, Manzocco L, Lerici CR. Antioxidant properties of coffee brews in relation to the roasting degree. LWT - Food Sci Tech 1997; 30: 292-7.

15. Braga GC, Couto SM, Hara T, Neto JTPA. Mechanical behavior of macadamia nut under compression loading. J Agric Eng Res 1999; 72: 239-45.

16. Ohinishi M, Morishita H, Iwahasni H, Toda S, Shiratika Y, Kimura $\mathbf{M}$, et al. Inhibitory effects of chlorogenic acids on linoleic acid peroxidation and hemolysis. Phytochemistry 1994; 36: $579-83$.

17. Singleton VL, Rossi JA. Colorimetry of total phenolics with phosphomolybdic-phosphotungstic acid reagents. Am J Enol Viticult 1965; 16: 144-58.

18. Alasalvar C, Karamac M, Kosinska A, Rybarczyk A, Shahidi F, Amarowicz R. Antioxidant activity of hazelnut Skin phenolics. J Agric Food Chem 2009; 57: 4645-50.

19. Naczk M, Amarowicz R, Zadernowski R, Pegg RB, Shahidi F. Antioxidant activity of crude phenolic extracts from wild blueberry leaves. Pol J Food Nutr Sci 2003; 12/13: 166-9.
20. Summa C, Raposo FC, McCourt J, Lo Scalzo R, Wagner KH, Elmadfa I. Effect of roasting on the radical scavenging activity of cocoa beans. Eur Food Res Tech 2006; 222: 368-75.

21. Kornsteiner M, Wagner KH, Elmadfa I. Tocopherols and total phenolics in 10 different nut types. Food Chem 2006; 98: 381-7.

22. Krings U, Berger RG. Antioxidant activity of some roasted foods. Food Chem 2001; 72: 223-9.

23. Pereira BLB, Leone M. Resistant starch in cassava products. Food Sci Tech 2014; 34: 298-302.

24. Pereira KD. Amido resistente, a última geração no controle de energia e digestão saudável. Ciência e Tecnologia de Alimentos 2007; 27: 88-92.

25. Marconi E, Ruggeri S, Cappelloni M, Leonardi D, Carnovale E. Physicochemical, nutritional, and microstructural characteristics of chickpeas (Cicer arietinum L.) and common beans (Phaseolus vulgaris L.) following microwave cooking. J Agric Food Chem 2000; 48: 5986-94.

26. Kong F, Singh RP. Digestion of raw and roasted almonds in simulated gastric environment. Food Biophys 2009; 4: $365-77$.

27. Vanga SK, Singh A, Kalkan F, Gariepy Y, Orsat V, Raghavan V. Effect of thermal and high electric fields on secondary structure of Peanut protein. International Journal of Food Properties 2015. doi: http://dx.doi.org/10.1080/10942912.2015.1071841

28. Holter JA, Reid TJ. Relationship between the concentrations of crude protein and apparently digestible protein in forages. J Anim Sci 1959; 18: 1339-49.

\section{*Fatih Kalkan}

Department of Bioresource Engineering

Faculty of Agriculture and Environmental Studies

McGill University, Sainte-Anne-de-Bellevue, QC

Canada H9X3V9

Email: fatihkalkan00।7@hotmail.com 